\title{
ARACHIDONIC ACID METABOLISM IN GLUCOCORTICOID-INDUCED HYPERTENSION
}

\author{
Yi Zhang, ${ }^{*}$ Lexian Hu, ${ }^{*}$ Trevor A Mori, ${ }^{\dagger \neq}$ Anne Barden, ${ }^{\dagger \ddagger}$ Kevin D Croft ${ }^{\dagger \ddagger}$ and Judith A Whitworth* \\ *The High Blood Pressure Research Unit, The John Curtin School of Medical Research, The Australian National University, \\ Canberra, Australian Capital Territory, 'School of Medicine and Pharmacology, University of Western Australia and \\ ${ }^{\ddagger}$ The Cardiovascular Research Centre, Perth, Western Australia, Australia
}

\section{SUMMARY}

1. Products of metabolism of arachidonic acid, such as 20hydroxyeicosatetraenoic acid (20-HETE), thromboxane $\mathrm{A}_{2}$ $\left(\mathrm{TXA}_{2}\right)$ and prostaglandin $\mathrm{I}_{2}\left(\mathrm{PGI}_{2}\right)$, regulate vascular tone. Among them, 20-HETE is a potent constrictor in small arteries that also has natriuretic properties. The present study investigated changes in urinary concentrations of 20-HETE and metabolites of TXA $_{2}$ and PGI $_{2}$ in glucocorticoid-hypertension in rats, a sodium-independent model.

2. Male Sprague-Dawley rats were treated with saline, adrenocorticotrophic hormone (ACTH; $0.2 \mathrm{mg} / \mathrm{kg}$ ) or dexamethasone $(20 \mu \mathrm{g} / \mathrm{kg})$ by daily s.c. injection for 12 days. Systolic blood pressure (SBP) was measured using the tail-cuff method. Metabolic cages were used for $24 \mathrm{~h}$ urine collection. Thymus weight and urinary concentrations of 20-HETE, TXA $\mathrm{A}_{2}$ and $\mathrm{PGI}_{2}$ were determined.

3. In the present study, SBP was increased by both ACTH (from $102 \pm 2$ to $134 \pm 7 \mathrm{mmHg} ; n=10 ; P<0.01)$ and dexamethasone (from $106 \pm 5$ to $122 \pm 4 \mathrm{mmHg} ; n=10 ; P<0.01$ ). Thymus weight, a marker for glucocorticoid activity, was significantly decreased by both ACTH and dexamethasone (56 \pm 9 and $76 \pm 5 \mathrm{mg} / 100 \mathrm{~g}$ bodyweight, respectively; $\left.n=10 ; P^{\prime}<0.01\right)$ compared with the saline control $(151 \pm 5 \mathrm{mg} / 100 \mathrm{~g}$ bodyweight; $n=20$ ). Urinary 20-HETE excretion was increased by ACTH $\left(501 \pm 115 \mathrm{pmol} / \mathrm{g}\right.$ creatinine; $\left.n=10 ; P^{\prime}<0.05\right)$ but not by dexamethasone $(126 \pm 13 \mathrm{pmol} / \mathrm{g}$ creatinine; $n=10)$ compared with the saline control $(219 \pm 54 \mathrm{pmol} / \mathrm{g}$ creatinine; $n=20)$. Neither ACTH nor dexamethasone affected urinary excretion of $\mathrm{TXB}_{2}$ or $\mathrm{PGI}_{2}$ compared with the saline control.

4. In conclusion, ACTH but not dexamethasone increased urinary 20-HETE excretion in male Sprague-Dawley rats. Urinary concentrations of the metabolites $\mathrm{TXB}_{2}$ and $\mathrm{PGI}_{2}$ were unchanged in both models of glucocorticoid-hypertension. The vasoconstrictor 20-HETE may play a role in the genesis of ACTH-induced hypertension.

Key words: arachidonic acid, glucocorticoid, 20hydroxyeicosatetraenoic acid (20-HETE), hypertension.

Correspondence: Professor Judith A Whitworth, The High Blood Pressure Research Unit, The John Curtin School of Medical Research, Building 131, Garran Road, The Australian National University, Canberra, ACT 0200, Australia. Email: judith.whitworth@anu.edu.au

Received 21 June 2007; revision 26 July 2007; accepted 18 September 2007.

(C) 2007 The Australian National University

Journal compilation (C 2007 Blackwell Publishing Asia Pty Ltd

\section{INTRODUCTION}

The products of metabolism of arachidonic acid (AA), such as thromboxane (TX) $\mathrm{A}_{2}$, prostaglandin $\mathrm{I}_{2}\left(\mathrm{PGI}_{2}\right)$ and 20-hydroxyeicosatetraenoic acid (20-HETE), regulate vascular tone. Thromboxane $\mathrm{A}_{2}$, a potent vasoconstrictor, is a product of AA catalysed by cyclo-oxygenase and thromboxane synthase. ${ }^{1}$ Because of its short half-life, it is measured by assaying its stable metabolites, such as $\mathrm{TXB}_{2} .{ }^{2}$ In essential hypertensive patients, urinary 11-dehydro- $\mathrm{TXB}_{2}$ concentrations were significantly higher than in normotensive controls, indicating that thromboxane excess may increase blood pressure. ${ }^{3}$ Angiotensin II treatment significantly increased systolic blood pressure (SBP) in wild-type but not $\mathrm{TXA}_{2}$-knockout mice. ${ }^{4}$ Treatment with ridogrel (a $\mathrm{TXA}_{2}$ antagonist and synthesis inhibitor) reversed the increase in SBP in uraemic rats. ${ }^{5}$ Administration of the synthetic glucocorticoid dexamethasone (Dex; $2.5 \mathrm{mg} / \mathrm{L}$ in drinking water; approximately $0.3 \mathrm{mg} / \mathrm{kg}$ per day) to male Sprague-Dawley rats fed a saturated fat-enriched diet significantly decreased serum $\mathrm{TXB}_{2}$ by $76-83 \%{ }^{6}$ Furthermore, treatment with very high doses of Dex $(1 \mathrm{mg} / \mathrm{kg}$ per day, i.m.) in newborn rabbits significantly decreased mean plasma $\mathrm{TXB}_{2}$ following exposure to a hyperoxic environment. ${ }^{7}$

Prostaglandin $\mathrm{I}_{2}$ is a vasodilator generated from AA by cyclooxygenase and prostacyclin synthase. ${ }^{1}$ Deficiency of prostacyclin may be important in the pathophysiology of hypertension. ${ }^{8} \mathrm{~A}$ significantly lower plasma concentration of 6-keto- $\mathrm{PGF}_{1 \alpha}$ (a stable major metabolite of prostacyclin) was detected in Dahl-salt-sensitive rats compared with salt-resistant rats. ${ }^{8}$ Administration of buthioninesulphoximine (depleting glutathione to induce oxidative stress) to male Sprague-Dawley rats significantly increased mean arterial pressure, accompanied by a decrease in plasma prostacyclin compared with controls. ${ }^{9}$ Dexamethasone $(3 \mathrm{mg} / \mathrm{L}$ in drinking water; approximately $0.36 \mathrm{mg} / \mathrm{kg}$ per day for 7 days) inhibited synthesis of $\mathrm{PGI}_{2}$ in Wistar rats. ${ }^{10}$ Conversely, plasma 6-keto- $\mathrm{PGF}_{1 \alpha}$ was significantly higher in Dex $(1 \mathrm{mg} / \mathrm{kg}$ per day, i.m.)-treated newborn rabbits exposed to hyperoxia compared with controls. ${ }^{7}$

20-Hydroxyeicosatetraenoic acid is a potent constrictor in small arteries of renal, cerebral and mesenteric arteries. It depolarizes vascular smooth muscle by blocking calcium-sensitive potassium $\left(\mathrm{K}_{\mathrm{Ca}}\right)$ channels and may serve as an endogenous intracellular regulator of the $\mathrm{K}^{+}$channel in arteriolar smooth muscle cells. ${ }^{11}$ 20-Hydroxyeicosatetraenoic acid increases intracellular $\mathrm{Ca}^{2+}$ concentrations via inhibition of $\mathrm{K}_{\mathrm{Ca}}$ channels and by a direct effect on L-type Ca channels. ${ }^{11}$ Conversely, 20-HETE also has naturetic properties and has been implicated in playing a protective role in models of salt-dependent hypertension. ${ }^{12}$ However, the effect of glucocorticoids on 20-HETE production is not known. 
The aim of the present study was to investigate the effects of adrenocorticotrophic hormone (ACTH), which raises blood pressure by increasing endogenous corticosterone concentrations, ${ }^{13}$ and low-dose dexamethasone on these AA metabolites in male SpragueDawley rats.

\section{METHODS}

\section{Experimental animals}

Forty male Sprague-Dawley rats (approximately $200 \mathrm{~g}$; Animal Resources Centre, Perth, WA, Australia) were used in these studies, which were approved by the Animal Experimental Ethics Committee of the Australian National University (Protocol number J.HB. 16.03 and 18.04). Rats were housed in plastic cages at constant temperature of $20-22^{\circ} \mathrm{C}$, humidity $30-$ $31 \%$ and under a $12 \mathrm{~h} \mathrm{light-dark} \mathrm{cycle.} \mathrm{Rats} \mathrm{had} \mathrm{free} \mathrm{access} \mathrm{to} \mathrm{standard}$ commercial feed and drinking water. Rats were handled and acclimatized to the equipment for 2 weeks before experiments were started.

\section{Experimental protocol}

Adrenocorticotrophic hormone $(0.2 \mathrm{mg} / \mathrm{kg}$, in a volume of $1 \mathrm{~mL} / \mathrm{kg}$; Novartis Pharmaceuticals, North Ryde, NSW, Australia), Dex (20 $\mu \mathrm{g} / \mathrm{kg}$ per day, in a volume of $1 \mathrm{~mL} / \mathrm{kg}$; David Bull Laboratories, Mulgrave, Victoria, Australia) or saline ( $1 \mathrm{~mL} / \mathrm{kg}$ per day) was administered subcutaneously. After 4 control days, rats were randomly divided into three groups and treated with saline vehicle (Group 1; $n=20$ ), ACTH (Group 2; $n=10$ ) or Dex (Group 3; $n=10$ ) for 13 days. Treatment day was defined as ' $\mathrm{T}$ '.

\section{Systolic blood pressure and bodyweight measurements}

Systolic blood pressure was measured at 0900-1200 hours on alternative days using a heating plate $\left(\right.$ at $40^{\circ} \mathrm{C}$ ) and tail-cuff system (Narco Biosystems, Houston, TX, USA). Rats were put on the heating plate for $25-50 \mathrm{~min}$. The mean of four recordings (difference $\leq 10 \mathrm{mmHg}$ ) was accepted as SBP for each rat. Bodyweight was measured on alternative days after blood pressure measurement.

\section{Metabolic measurement}

On the last treatment day, rats were put into individual metabolic cages (Mascot Wire, Sydney, NSW, Australia) for $24 \mathrm{~h}$ for urine collection and measurement of food/water intake.

\section{Assays for urinary AA metabolites}

Twenty-four hour urine samples were collected prior to anaesthetic for assays of concentrations of 20-HETE and thromboxane and prostacyclin metabolites. Urinary 20-HETE concentrations were measured using electron-capture negative-ion gas chromatography-mass spectrometry, as described previously. ${ }^{14}$ Urinary $\mathrm{TXB}_{2}$ and $\mathrm{PGI}_{2}$ concentrations were measured using enzyme immunoassays (Assay Designs, Ann Arbor, MI, USA) after extraction, as described previously. ${ }^{15}$ The adequacy of urine collection was ensured by correcting for urinary creatinine concentrations.

\section{Thymus weight}

After rats had been killed, their thymus was isolated and measured as an in vivo glucocorticoid activity marker. Thymus weight was expressed as $\mathrm{mg} / 100 \mathrm{~g}$ bodyweight.

\section{Lucigenin chemiluminescence assay}

After rats had been killed, their thoracic aorta was removed and cut into two $5 \mathrm{~mm}$ segments. Lucigenin-enhanced chemiluminescence was used to measure
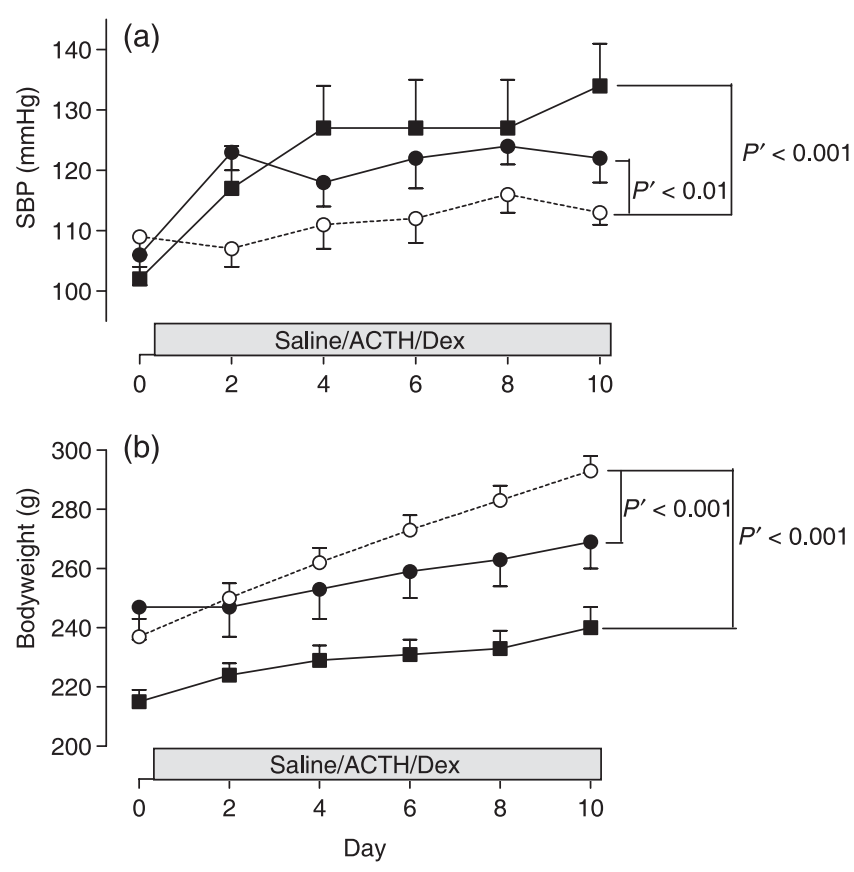

Fig. 1 (a) Systolic blood pressure (SBP) and (b) bodyweight of saline- $(\bigcirc)$, adrenocorticotrophic hormone- (ACTH; $\mathbf{\square})$ and dexamethasone-treated (Dex; ) rats.

NADPH-stimulated superoxide production from aortic rings. The final concentration of lucigenin (Sigma-Aldrich, St Louis, MO, USA) was $5 \mu \mathrm{mol} / \mathrm{L}$. Superoxide production was expressed as count/s per mg dry aorta weight.

\section{Statistical analysis}

Data were analysed using sPss version 11.0 (SPSS, Chicago, IL, USA); Greenhouse-Geisser $P$ and $P^{\prime}$ values (the Bonferroni-corrected value) $\leq 0.05$ were regarded as significant. All statistical analyses used raw data. Systolic blood pressure and bodyweight within and between groups were analysed using repeated-measures ANOVA. Urinary excretions of AA metabolites, thymus weight, lucigenin chemiluminescence and metabolic data between different groups were analysed using unpaired Student's $t$-test. Data are expressed as the mean \pm SEM.

\section{RESULTS}

\section{Systolic blood pressure}

Saline treatment had no significant effect on SBP $(109 \pm 3$ and $113 \pm 2 \mathrm{mmHg}$ on T0 and T10, respectively). Systolic blood pressure was significantly increased from T0 to T10 by both ACTH (from $102 \pm 2$ to $134 \pm 7 \mathrm{mmHg} ; P<0.001$ ) and Dex (from $106 \pm 5$ to $122 \pm 4 \mathrm{mmHg} ; P<0.01)$. Systolic blood pressure was high in both ACTH- $\left(P^{\prime}<0.001\right)$ and Dex-treated rats $\left(P^{\prime}<0.01\right)$ compared with saline-treated rats (Fig. 1a).

\section{Bodyweight}

Bodyweight was increased from T0 to T10 in saline- (from $237 \pm 6$ to $293 \pm 5 \mathrm{~g} ; P<0.01$ ), ACTH- (from $215 \pm 4$ to $240 \pm 7 \mathrm{~g} ; P<0.01$ ) and Dex-treated rats (from $247 \pm 11$ to $269 \pm 9 \mathrm{~g} ; P<0.01$ ). Bodyweight gain was slower in ACTH- and Dex-treated rats compared with saline-treated rats $\left(P^{\prime}<0.001\right.$; Fig. 1b). 
(a)
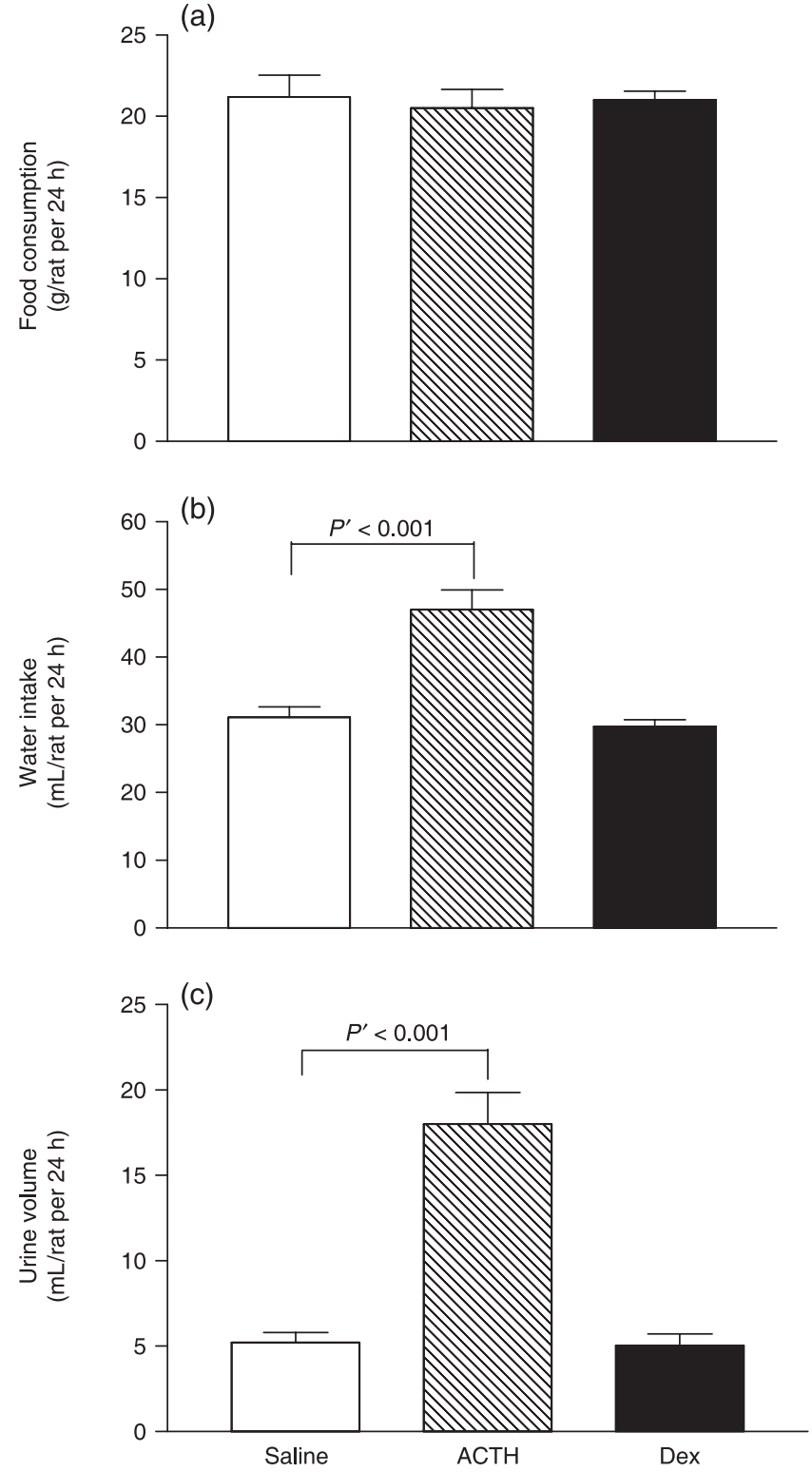

Fig. 2 Metabolic measurements. (a) Daily food consumption, (b) water intake and (c) urine volume of saline-, adrenocorticotrophic hormone $(\mathrm{ACTH})-$ and dexamethasone (Dex)-treated rats.

\section{Metabolic measurements}

Daily food consumption was similar in all three groups $(21 \pm 1 \mathrm{~g} / \mathrm{rat}$, $n=10-20$ in each group; Fig. 2a). Adrenocorticotrophic hormone increased daily water consumption $(47 \pm 3 \mathrm{~mL} / \mathrm{rat})$, whereas Dex (20 $\mu \mathrm{g} / \mathrm{kg}$ per day) had no significant effect on daily water intake $(30 \pm 1 \mathrm{~mL} / \mathrm{rat})$ compared with saline-treated rats $(31 \pm 2 \mathrm{~mL} / \mathrm{rat}$; Fig. 2b). Twenty-four hour urine output was significantly increased by ACTH but not Dex compared with saline treatment $(18 \pm 2,5 \pm 1$ and $5 \pm 1 \mathrm{~mL} /$ rat, respectively; Fig. $2 \mathrm{c}$ ).

\section{Urinary AA metabolites}

Urinary 20-HETE excretion was higher in ACTH-treated animals compared with saline-treated rats $(501 \pm 115$ vs $219 \pm 54 \mathrm{pmol} / \mathrm{g}$ creatinine, respectively; $n=10$ and 18 , respectively; $P^{\prime}<0.05$ ). There was no significant difference in urinary 20-HETE excretion between the saline- and Dex-treated rats $(126 \pm 13 \mathrm{pmol} / \mathrm{g}$ creatinine; Fig. 3a). There was no significant difference in urinary $\mathrm{TXB}_{2}$ excretion between the saline ( $n=18)$-, ACTH- and Dex-treated rats $(320 \pm 42$, $379 \pm 50$ and $222 \pm 10 \mathrm{ng} / \mathrm{g}$ creatinine, respectively; Fig. 3b). Urinary $\mathrm{PGI}_{2}$ excretion was similar in the saline $(n=18)$-, ACTH- and Dex-treated rats $(7.9 \pm 1.2,8.3 \pm 1.3$ and $4.5 \pm 0.3 \mu \mathrm{g} / \mathrm{g}$ creatinine, respectively; Fig. 3c).

\section{Thymus weight}

Both ACTH and Dex treatment significantly decreased rat thymus weight compared with the saline control $(56 \pm 9,76 \pm 5$ and $151 \pm 5 \mathrm{mg} / 100 \mathrm{~g}$ bodyweight, respectively; $P^{\prime}<0.001$; Fig. 4a).

\section{Production of superoxide in the aorta}

Lucigenin-enhanced chemiluminescence in aortic segments was higher in ACTH-treated rats compared with saline-treated rats (183 \pm 27 vs $108 \pm 14$ count/s per mg, respectively; $\left.P^{\prime}<0.05\right)$, but similar between the saline- and Dex-treated ( $84 \pm 14$ count/s per mg; $n=9$ ) groups (Fig. 4b).

\section{DISCUSSION}

In the present study, both ACTH $(0.2 \mathrm{mg} / \mathrm{kg}$ per day, s.c. $)$ and Dex $(20 \mu \mathrm{g} / \mathrm{kg}$ per day, s.c.) treatment significantly increased SBP and decreased bodyweight and thymus weight in Sprague-Dawley rats, consistent with previous publications. ${ }^{16}$
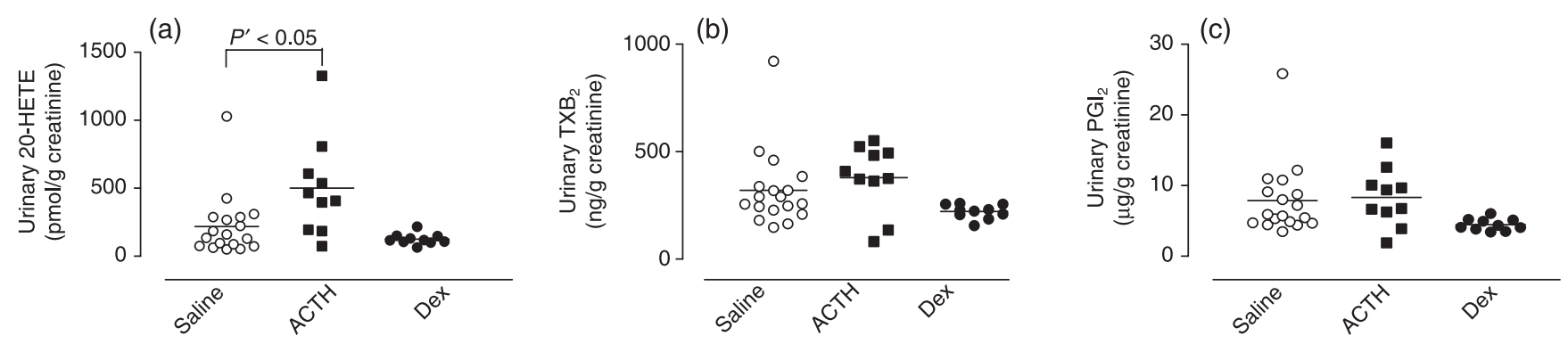

Fig. 3 Concentrations of urinary arachidonic acid metabolites (corrected by urinary creatinine levels): (a) 20-hydroxyeicosatetraenoic acid (20-HETE), (b) thromboxane $\mathrm{B}_{2}\left(\mathrm{TXB}_{2}\right)$ and (c) prostaglandin $\mathrm{I}_{2}\left(\mathrm{PGI}_{2}\right)$ in saline- $(\bigcirc)$, adrenocorticotrophic hormone- $(\mathrm{ACTH} ; \mathbf{\square})$ and dexamethasone-treated $($ Dex; $\bullet$ rats. 

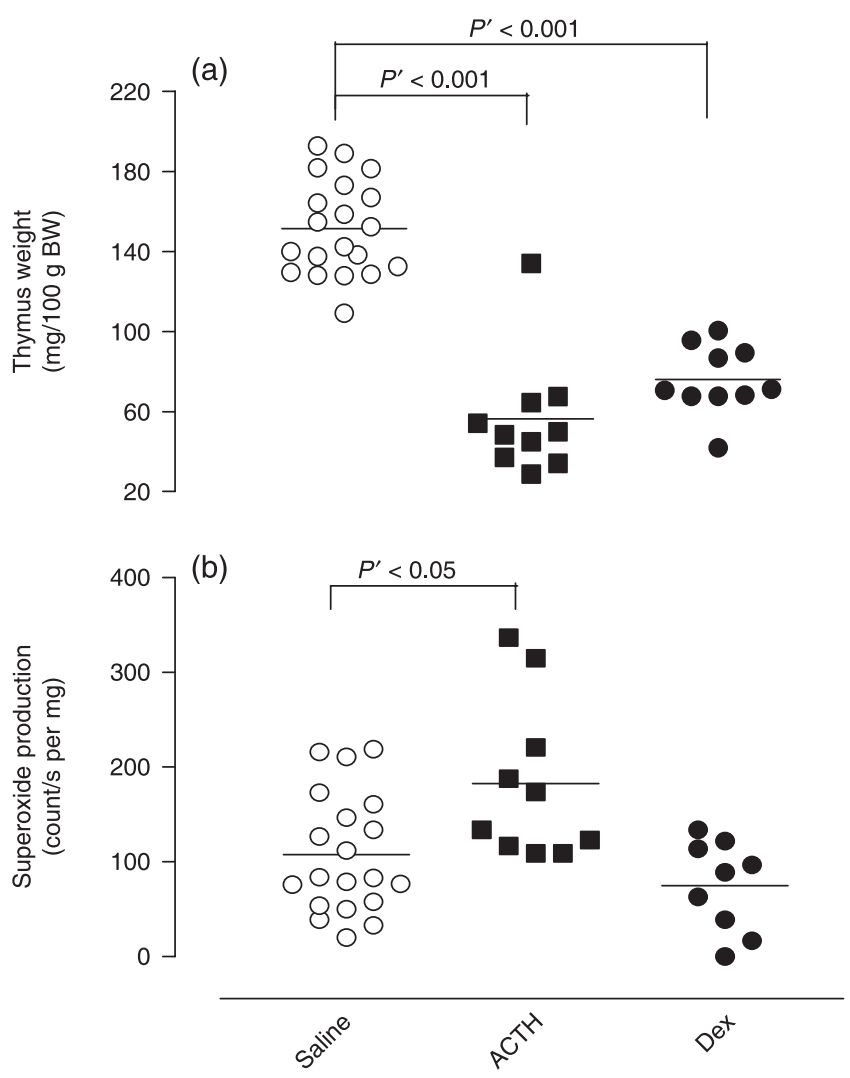

Fig. 4 (a) Thymus weight and (b) aortic superoxide production in rats treated with saline $(\bigcirc)$, adrenocorticotrophic hormone $(\mathbf{\square})$ and dexamethasone (๑). BW, bodyweight.

Neither ACTH nor Dex had any effect on food intake. Adrenocorticotrophic hormone, but not Dex, increased water consumption and $24 \mathrm{~h}$ urine volume. The effects of ACTH on food and water consumption and urinary output are consistent with previous publications. ${ }^{17}$ The metabolic effects of Dex vary between species and depend on dose. In sheep, administration of Dex at $24 \mathrm{mg}$ /day for 5 days increased water intake (only on Treatment Day 1) and urine output. ${ }^{18}$ However, in Sprague-Dawley rats, high-dose Dex ( $5 \mathrm{mg}$ /day per rat (approximately $23-25 \mathrm{mg} / \mathrm{kg}$ per day), s.c., for 3 weeks) had no effect on water intake, but increased urine volume. ${ }^{19}$ In humans, Dex orally at $8 \mathrm{mg} /$ day for 5 days enhanced urine volume. ${ }^{20}$ In the present study, the low dose of Dex used $(20 \mu \mathrm{g} / \mathrm{kg}$ per day, s.c.) increased SBP without any significant effect on these metabolic parameters.

We have demonstrated previously that $\mathrm{ACTH}$-induced hypertension is associated with increased oxidative stress, as determined by plasma $\mathrm{F}_{2}$-isoprostane concentrations, ${ }^{16}$ and superoxide, measured by lucigenin-enhanced chemiluminescence. ${ }^{21}$ In the present study, aortic superoxide production, measured by lucigenin-enhanced chemiluminescence, was increased by ACTH, confirming these previous findings. However, in Dex-treated rats, although plasma $\mathrm{F}_{2}$-isoprostane concentrations have been reported to be increased in previous studies, ${ }^{16}$ there was no increase in lucigenin-enhanced chemiluminescence.

The major finding of the present study was that ACTH (but not Dex) treatment increased urinary 20-HETE excretion. In hypertensive humans, urinary 20-HETE excretion is positively correlated with diastolic blood pressure. ${ }^{22}$ Formation of 20-HETE is inhibited by nitric oxide (NO), which binds to the catalytic heme site in the cytochrome 450 4A (CYP4A) enzyme. ${ }^{23}$ We have demonstrated previously that ACTH treatment inhibits inducible and endothelial NO synthase (NOS) expression in kidney ${ }^{24}$ and lowers plasma nitrate/nitrite $\left(\mathrm{NO}_{\mathrm{x}}\right)$, L-arginine and L-citrulline concentrations. ${ }^{25}$ Feeding L-arginine, a NOS precursor, reversed ACTH-induced hypertension in Sprague-Dawley rats. ${ }^{25}$ Accordingly, ACTH-induced 20-HETE overproduction may be the result of NO deficiency. 20Hydroxyeicosatetraenoic acid has vascular prohypertensive and renal tubular antihypertensive properties. Adrenocorticotrophic hormone-induced hypertension is not sodium dependent, ${ }^{26}$ so any effects of 20-HETE on blood pressure in this model would be likely to reflect vasoconstriction rather than changes in sodium excretion.

It has been demonstrated that the 20-HETE analogue WIT003 stimulates superoxide formation in human microvascular endothelial cells. ${ }^{27}$ Arteries from CYP4A-overexpressing rats produced more 20-HETE, less NO and displayed higher levels of oxidative stress, as measured by increased generation of superoxide and increased expression of nitrotyrosine and gp91phox..$^{28}$ Inhibition of 20-HETE production by HET0016 reduced androgen-induced interlobar arterial production of superoxide and the levels of gp91-phox and p47-phox proteins and decreased blood pressure in Sprague-Dawley rats. ${ }^{29}$ In hypertensive patients, urinary 20-HETE excretion is positively associated $\mathrm{F}_{2}$-isoprostanes. ${ }^{22}$ We have demonstrated previously that plasma $\mathrm{F}_{2}$-isoprostane concentrations are increased in ACTH- and Dex-induced hypertension and that chronic antioxidant therapy (e.g. tempol and apocynin) prevent and reverse both ACTH- and Dex-induced hypertension, ${ }^{30-33}$ indicating that oxidative stress plays an important role in both models of hypertension. However, in the present study, only ACTH-induced hypertension was associated with increased 20-HETE and superoxide production. There is no significant correlation between superoxide and 20HETET production $\left(r^{2}=0.085 ; P=0.0799\right)$.

The role of thromboxane in hypertension varies in different models. A marked increase in urinary $\mathrm{TXB}_{2}$ levels was found in $N^{\mathrm{G}}$-nitro-Larginine methyl ester-induced hypertensive male Wistar rats. ${ }^{34}$ Chronic angiotensin II infusion raised blood pressure more in wild-type mice than $\mathrm{TXA}_{2}$-knockout mice. ${ }^{4}$ However, U63557A, a thromboxane synthetase inhibitor, did not reverse cyclosporineinduced hypertension in sheep. ${ }^{35}$ High-dose Dex $(0.142-0.3 \mathrm{mg} / \mathrm{kg}$ per day) treatment decreased serum $\mathrm{TXB}_{2}$ in Sprague-Dawley rats fed a high-fat $\operatorname{diet}^{6}$ and in one-kidney, one-clip rats. ${ }^{36}$ In the present study, both ACTH and low-dose Dex increased blood pressure, but neither altered urinary $\mathrm{TXB}_{2}$ excretion, suggesting that thromboxane may not play a major role in glucocorticoid-induced hypertension in rats.

Vasodilator prostanoid deficiency may also be important in experimental hypertension. A decrease was observed in plasma $\mathrm{PGI}_{2}$ in oxidative stress-induced hypertensive Sprague-Dawley rats ${ }^{9}$ and urinary 6-keto- $\mathrm{PGF}_{1 \alpha}$ concentrations were significantly lower in uraemic rats compared with controls. ${ }^{5}$ In the present study, neither ACTH nor Dex had any effect on urinary $\mathrm{PGI}_{2}$ metabolite excretion. Previous studies investigating the effect of Dex on $\mathrm{PGI}_{2}$ using high doses of Dex gave inconsistent results. ${ }^{10,36}$ In Wistar rats, Dex $(3 \mathrm{mg} / \mathrm{L}$ in drinking water; approximately $0.3 \mathrm{mg} / \mathrm{kg}$ per day) inhibited the synthesis of $\mathrm{PGI}_{2}$ in the kidney (measured by $24 \mathrm{~h}$ urinary excretion of PGI-M, a major metabolite of $\left.\mathrm{PGI}_{2}\right)$. $^{9}$ Administration of Dex $(2.5 \mathrm{mg} / \mathrm{kg}$ per week, s.c.) to rats produced a biphasic effect on 
urinary $\mathrm{PGF}_{2 \alpha}$ excretion. ${ }^{37}$ In that study, ${ }^{37}$ after Dex Treatment Day 1 , there was a significant decrease in urinary $\mathrm{PGF}_{2 \alpha}$ excretion compared with control; however, after Day 5 and Day 14, urinary PGF $_{2 \alpha}$ excretion was higher than in the control group. In Sprague-Dawley rats, immobilization stress increased plasma ACTH and corticosterone concentrations and aortic ring 6-keto- $\mathrm{PGF}_{1 \alpha}$ levels; however, coadministration of ACTH $(2 \mu \mathrm{g} / \mathrm{kg})$ and noradreanline, which also raised plasma levels of $\mathrm{ACTH}$, corticosterone and noradrenaline to peak stress levels, did not increase 6-keto- $\mathrm{PGF}_{1 \alpha}$ levels in aortic tissue. ${ }^{38}$ Urinary 6-keto-PGF ${ }_{1 \alpha}$ concentrations were unchanged in cortisol-treated humans. ${ }^{39}$ Although uterine concentrations of 6-oxoPGF $1 \alpha$ (a hydrolysis product of $\mathrm{PGI}_{2}$ ) in $\mathrm{ACTH}$-treated sheep during labour were elevated, ${ }^{40}$ treatment of sheep with prostacyclin did not prevent ACTH-induced hypertension, ${ }^{41}$ suggesting that $\mathrm{PGI}_{2}$ may not play an important role in glucocorticoid-induced hypertension. However, we cannot completely exclude the possibility of having underestimated the role of thromboxane and deficiency of $\mathrm{PGI}_{2}$ in glucocorticoid-induced hypertension because urinary excretion rate may not reflect tissue levels.

In conclusion, in male Sprague-Dawley rats, ACTH but not Dex increased urinary 20-HETE excretion. Urinary excretion of $\mathrm{TXA}_{2}$ and $\mathrm{PGI}_{2}$ metabolites was not changed in either model of glucocorticoidhypertension. 20-Hydroxyeicosatetraenoic acid may play a role in ACTH-induced hypertension and studies investigating the effect of a 20-HETE inhibitor on glucocorticoid-induced hypertension are warranted.

\section{ACKNOWLEDGEMENT}

Adrenocorticotrophic hormone (Synacthen Depot; Tetracosactrin) was generously provided by Novartis Pharmaceuticals Australia Pty Ltd (North Ryde, NSW, Australia).

\section{REFERENCES}

1. Needleman P, Turk J, Jakschik BA, Morrison AR, Lefkowith JB. Arachidonic acid metabolism. Annu. Rev. Biochem. 1986; 55: 69-102.

2. Ally AI, Horrobin DF. Thromboxane $\mathrm{A}_{2}$ in blood vessel walls and its physiological significance: Relevance to thrombosis and hypertension. Prostaglandins Leukot. Med. 1980; 4: 431-8.

3. Minuz P, Patrignani P, Gaino S et al. Determinants of platelet activation in human essential hypertension. Hypertension 2004; 43: 64-70.

4. Francois H, Athirakul K, Mao L, Rockman H, Coffman TM. Role for thromboxane receptors in angiotensin-II-induced hypertension. Hypertension 2004; 43: 364-9.

5. Lariviere R, Moreau C, Rodrigue ME, Lebel M. Thromboxane blockade reduces blood pressure and progression of renal failure independent of endothelin-1 in uremic rats. Prostaglandins Leukot. Essent. Fatty Acids 2004; 71: 103-9.

6. Codde JP, Beilin LJ. Dietary fish oil prevents dexamethasone induced hypertension in the rat. Clin. Sci. 1985; 69: 691-9.

7. Ozaki N, Beharry K, Nishihara KC, Akmal Y, Ang JG, Modanlou HD. Differential regulation of prostacyclin and thromboxane by dexamethasone and celecoxib during oxidative stress in newborn rabbits. Prostaglandins Other Lipid Mediat. 2002; 70: 61-78.

8. Bayorh MA, Ganafa AA, Socci RR, Silvestrov N, Abukhalaf IK. The role of oxidative stress in salt-induced hypertension. Am. J. Hypertens. 2004; 17: 31-6.

9. Bayorh MA, Ganafa AA, Socci RR, Eatman D, Silvestrov N, Abukhalaf IK. Effect of losartan on oxidative stress-induced hypertension in Sprague-Dawley rats. Am. J. Hypertens. 2003; 16: 38792 .
10. Falardeau $\mathrm{P}$, Martineau A. Prostaglandin $\mathrm{I}_{2}$ and glucocorticoid-induced rise in arterial pressure in the rat. J. Hypertens. 1989; 7: 625-32.

11. Miyata N, Roman RJ. Role of 20-hydroxyeicosatetraenoic acid (20HETE) in vascular system. J. Smooth Muscle Res. 2005; 41: 17593.

12. Hoagland KM, Maier KG, Roman RJ. Contributions of 20-HETE to the antihypertensive effects of tempol in Dahl salt-sensitive rats. Hypertension 2003; 41: 697-702.

13. Mangos GJ, Turner SW, Fraser TB, Whitworth JA. The role of corticosterone in corticotrophin (ACTH)-induced hypertension in the rat. J. Hypertens. 2000; 18: 1849-55.

14. Ward NC, Rivera J, Hodgson J et al. Urinary 20-hydroxyeicosatetraenoic acid is associated with endothelial dysfunction in humans. Circulation 2004; 110: 438-43.

15. Croft KD, Beilin LJ, Vandongen R, Codde JP, Barden A. Onset of changes in phospholipid fatty acid composition and prostaglandin synthesis following dietary manipulation with n-6 and n-3 fatty acids in the rat. Biochim. Biophys. Acta 1985; 834: 316-23.

16. Miao Y, Zhang Y, Lim PS et al. Folic acid prevents and partially reverses glucocorticoid-induced hypertension in the rat. Am. J. Hypertens. 2007; 20: 304-10.

17. Turner SW, Wen C, Li M, Fraser TB, Whitworth JA. Adrenocorticotrophin dose-response relationships in the rat: Haemodynamic, metabolic and hormonal effects. J. Hypertens. 1998; 16: 593-600.

18. Whitworth JA, Coghlan JP, Denton DA, Graham WF, Humphery TJ, Scoggins BA. Comparison of the effects of 'glucocorticoid' and 'mineralocortocoid' infusions on blood pressure in sheep. Clin. Exp. Hypertens. 1979; 1: 649-63.

19. Kalimi M. Role of antiglucocorticoid RU 486 on dexamethasoneinduced hypertension in rats. Am. J. Physiol. 1989; 256: E682-5.

20. Whitworth JA, Gordon D, Andrews J, Scoggins BA. The hypertensive effect of synthetic glucocorticoids in man: Role of sodium and volume. J. Hypertens. 1989; 7: 537-49.

21. Mondo CK, Zhang Y, Possamai V et al. $N$-Acetylcysteine partially prevents but does not reverse ACTH-induced hypertension in the rat. Clin. Exp. Hypertens. 2006; 28: 73-84.

22. Ward NC, Puddey IB, Hodgson JM, Beilin LJ, Croft KD. Urinary 20hydroxyeicosatetraenoic acid excretion is associated with oxidative stress in hypertensive subjects. Free Radic. Biol. Med. 2005; 38: 10326.

23. Roman RJ. P-450 metabolites of arachidonic acid in the control of cardiovascular function. Physiol. Rev. 2002; 82: 131-85.

24. Lou YK, Wen C, Li M et al. Decreased renal expression of nitric oxide synthase isoforms in adrenocorticotropin-induced and corticosteroneinduced hypertension. Hypertension 2001; 37: 1164-70.

25. Wen C, Li M, Fraser T, Wang J, Turner SW, Whitworth JA. L-Arginine partially reverses established adrenocorticotrophin-induced hypertension and nitric oxide deficiency in the rat. Blood Pressure 2000; 9: 298-304.

26. Li M, Whitworth JA. ACTH hypertension in the rat: Role of sodium chloride. Clin. Exp. Hypertens. 1992; 14: 567-85.

27. Guo AM, Arbab AS, Falck JR et al. Activation of vascular endothelial growth factor through reactive oxygen species mediates 20hydroxyeicosatetraenoic acid-induced endothelial cell proliferation. J. Pharmacol. Exp. Ther. 2007; 321: 18-27.

28. Wang JS, Singh H, Zhang F et al. Endothelial dysfunction and hypertension in rats transduced with CYP4A2 adenovirus. Circ. Res. 2006; 98: $962-29$.

29. Singh H, Cheng J, Deng H et al. Vascular cytochrome P450 4A expression and 20-hydroxyeicosatetraenoic acid synthesis contribute to endothelial dysfunction in androgen-induced hypertension. Hypertension 2007; 50: $123-9$.

30. Zhang Y, Jang R, Mori TA et al. The anti-oxidant tempol reverses and partially prevents adrenocorticotropic hormone-induced hypertension in the rat. J. Hypertens. 2003; 21: 1513-18.

31. Zhang Y, Croft KD, Mori TA, Schyvens CG, McKenzie KUS, Whitworth JA. The anti-oxidant tempol prevents and partially reverses dexamethasone-induced hypertension in the rat. Am. J. Hypertens. 2004; 17: 260-26. 
32. Zhang Y, Chan MMK, Andrews MC et al. Apocynin but not allopurinol prevents and reverses ACTH-induced hypertension in the rat. Am.J. Hypertens. 2005; 18: 910-16.

33. Hu L, Zhang Y, Lim PS et al. Apocynin but not L-arginine prevents and reverses dexamethasone-induced hypertension in the rat. Am. J. Hypertens. 2006; 19: 413-18.

34. Alanko J, Jolma P, Koobi $\mathrm{P}$ et al. Prostacyclin and thromboxane $\mathrm{A}_{2}$ production in nitric oxide-deficient hypertension in vivo. Effects of high calcium diet and angiotensin receptor blockade. Prostaglandins Leukot. Essent. Fatty Acids 2003; 69: 345-50.

35. Tomida T, Numaguchi Y, Matsui H et al. Altered expression of prostacyclin synthase in a subset of the thick ascending limb cells and mesangial cells in 5/6-nephrectomized rats. Hypertens. Res. 2001; 24: 411-19.

36. McGowan HM, Vandongen R, Smith B. Dexamethasone attenuates reversal of hypertension in one-kidney, one-clip rats. Am. J. Physiol. 1988; 255: H717-21.
37. Erman A, Pitcock JA, Liston T, Brown P, Baer PG, Nasjletti A. Biphasic effect of dexamethasone on urinary prostaglandins in rats: Relation to alterations in renal medulla triglycerides and prostaglandin metabolism. Endocrinology 1987; 121: 1853-61.

38. Grimee $\mathrm{R}$, Wulfert $\mathrm{E}$. Acute stress in rats produces a rapid and sustained increase in prostacyclin production in aortic tissue: Dependence on corticosterone. Life Sci. 1995; 57: 69-81.

39. Whitworth JA, Williamson PM, Mangos G, Kelly JJ. Cardiovascular consequences of cortisol excess. Vasc. Health Risk Manag. 2005; 1: 291-9.

40. Evans CA, Kennedy TG, Patrick JE, Challis JR. Uterine prostaglandin concentrations in sheep during late pregnancy and adrenocorticotropininduced labor. Endocrinology 1981; 109: 1533-8.

41. Mason RT, Coghlan JP, Congiu M et al. Prostacyclin infusion does not prevent ACTH-induced hypertension in sheep. Prostaglandins Leukot. Med. $1985 ; 18$ : 261-9. 